
и бозентаном у больной идиопатической легочной гипертензией

ФБГУ "НИИ пульмонологии" ФМБА России: 105077, Россия, Москва, ул. 11-я Парковая, 32, корп. 4

\author{
S.N.Avdeev, N.A.Tsareva, G.V.Nekludova
}

\title{
Therapy of idiopathic pulmonary hypertension with combination of inhaled iloprost and bosentan
}

Key words: idiopathic pulmonary hypertension, combined therapy, inhaled iloprost, bosentan.

Ключевые слова: идиопатическая легочная артериальная гипертензия, комбинированная терапия, ингаляционный илопрост, бозентан.

Легочная артериальная гипертензия (ЛАГ) принадлежит к клинической группе редких заболеваний и характеризуется наличием прекапиллярной легочной гипертензии (ЛГ) при условии отсутствия других причин для ее развития вследствие респираторных причин, заболеваний сердца, тромбоэмболии легочной артерии (ЛА) и т. п. [1, 2]. В понятие "ЛАГ" включены различные заболевания (идиопатическая ЛАГ - ИЛАГ; ЛАГ, ассоциированная с системными заболеваниями соединительной ткани; врожденные пороки сердца; вирус иммунодефицита человека и т. п.), которые имеют сходную клиническую картину и идентичные морфологические изменения в дистальных ЛА [1-3]. ЛАГ считается орфанным заболеванием, ее распространенность, по данным разных национальных регистров, составляет от 15 до 52 случаев на 1 млн населения [4, 5]. ЛАГ характеризуется одышкой при физической нагрузке, ограничением работоспособности, развитием отеков, обмороками, сопровождается развитием прогрессирующей правожелудочковой (ПЖ) сердечной недостаточности и риском преждевременной смерти [1-3, 6].

Несмотря на появление международных согласительных документов и успехи в медикаментозной терапии, долгосрочный прогноз пациентов с ЛАГ остается достаточно пессимистичным. Согласно данным, полученным на основе крупных национальных регистров ЛАГ, 1-годичная летальность у пациентов с ИЛАГ и семейной / наследственной ЛАГ составляет $\approx 15 \%[7,8]$, а у больных ЛАГ, ассоциированной с системными заболеваниями соединительной ткани, достигает $30 \%$ [9].

В общие мероприятия ведения больных ЛАГ включены ограничение физической активности, вакцинация против гриппа и кислородотерапия (для больных с гипоксемией). Несмотря на отсутствие строгой доказательной базы, пациентам с ЛГ также назначается профилактическая терапия непрямыми антикоагулянтами, диуретиками (при явлениях венозного застоя) и дигоксин (при развитии тяжелой дисфункции ПЖ или мерцательной тахиаритмии) [1-3]. В настоящее время методы излечения ЛАГ неизвестны, однако в течение последних 10 лет появились препараты, при приеме которых уменьшаются симптомы, улучшается качество жизни и замедляется прогрессирование заболевания. В современную схему терапии, специально созданную для терапии ЛАГ, включены простаниды, антагонисты рецепторов эндотелина и ингибиторы фосфодиэстеразы-5 [1-3]. В России в настоящее время доступны 3 препарата для терапии ЛАГ - ингаляционный илопрост, бозентан и силденафил.

В ряде случаев при монотерапии ЛАГ-специфичными препаратами состояние пациентов не улучшается и через определенное время после начального улучшения при их использовании вновь наблюдается ухудшение течения ЛАГ. В такой ситуации требуется эскалация лекарственной терапии, чаще всегокомбинированной.

Представлен клинический случай успешного использования комбинированной терапии бозентаном (Tраклир ${ }^{\circledR}$, Actelion Pharmaceuticals) и ингаляционным илопростом (Вентавис ${ }^{\circledR}$, Байер Фарма $А Г$, Германия) у больной ИЛАГ.

\section{Клиническое наблюдение}

Больная Л. 44 лет обратилась за помощью к пульмонологу с жалобами на выраженную одышку и сухой кашель при минимальных физических нагрузках (IV балла по шкале mMRC), эпизоды сердцебиения, головокружения, отеки голеней и стоп.

Больная - по профессии преподаватель, никогда не курила, профессиональные вредности, употребление алкоголя и наркотиков отрицает. Среди перенесенных заболеваний были только упоминания о ежегодных эпизодах острых респираторных заболеваний.

Из анамнеза известно, что впервые одышка при физических нагрузках появилась $\approx 4$ лет назад. После многократных консультаций у различных врачей-специалистов были поставлены диаг- 
нозы: нейроциркуляторная астения, хронический бронхит, бронхиальная астма, миокардит; назначались различные препараты, включая бронхолитики, ингаляционные стероиды, $\beta$-блокаторы, антидепрессанты. Ни один из видов терапии не приводил к уменьшению симптомов, одышка постепенно прогрессировала. Около 1 года назад после проведения тщательного эхокардиографического (ЭхоКГ) исследования была заподозрена ЛГ, и пациентка была направлена в экспертный центр для дальнейшего обследования. После выполнения комплекса специализированных исследований, включая катетеризацию ЛА, была подтверждена ЛАГ (систолическое давление в ЛА - СДЛА - 60 мм рт. ст., среднее давление в ЛА - 39 мм рт. ст., давление заклинивания ЛА - 10 мм рт. ст., сердечный индекс - 2,5 л / мин / м $^{2}, \mathrm{SvO}_{2}-66 \%$, проба на вазореактивность с ингаляционным оксидом азота - отрицательная). Больной был поставлен диагноз "идиопатическая ЛАГ, функциональный класс (ФК) III (по классификации Всемирной организации здравоохранения - ВО3)" и назначена терапия варфарином (целевые значения международного нормализованного отношения - 2-3) и бозентаном (Траклир ${ }^{\circledR}$, Actelion Pharmaceuticals) в дозе 125 мкг 2 раза в сутки. При помощи данной терапии значительно улучшились самочувствие (уменьшилась одышка, повысилась толерантность к физической нагрузке - ТФН) и параметры центральной гемодинамики (снизилось СДЛА до 54 мм рт. ст., повысился сердечный индекс $\leq 3,1$ л / мин / м²). Однако через 7-8 мес. после начала терапии бозентаном состояние больной вновь стало ухудшаться: отмечено прогрессирование одышки и появление отеков ног.

При осмотре: пациентка в ясном сознании, индекс массы тела -25 кг / м², умеренные отеки стоп и голеней. Границы легких перкуторно не изменены, при аускультации по всей поверхности выслушивалось жесткое дыхание, хрипов не отмечено, частота дыхания - 20 в минуту. Насышение артериальной крови кислородом по данным пульсоксиметрии $\left(\mathrm{SpO}_{2}\right)$ в покое - $96 \%$. Границы сердца расширены, выслушивался систолический шум над трикуспидальным клапаном и акцент II тона над ЛА, частота сердечных сокращений - 98 в минуту, артериальное давление - 105 / 60 мм рт. ст.

При исследовании функции внешнего дыхания выявлены выраженные изменения диффузионной способности легких (56 \% долж.). Газовый состав артериальной крови (в дневное время суток при дыхании атмосферным воздухом): парциальное давление кислорода в артериальной крови - 72 мм рт. ст., парциальное давление углекислого газа в артериальной крови - 34 мм рт. ст., $\mathrm{pH}-7,44, \mathrm{HCO} 3$ - 23 ммоль / л, сатурация кислородом - $95 \%$.

Таблица 1

Показатели ЭхоКГ до и после терапии илопростом

\begin{tabular}{|l|c|c|}
\multicolumn{1}{|c|}{ Показатель } & Исходно & $\begin{array}{c}\text { На фоне терапии } \\
\text { илопростом }\end{array}$ \\
\hline $\mathrm{PG}_{\text {maxtric, мм рт. ст. }}$ & 67 & 60 \\
\hline СДЛА, мм рт. ст. & 82 & 75 \\
\hline ПЖ*, см & 4,4 & 4,0 \\
\hline ПП , см & $4,6 \times 5,1$ & $4,2 \times 4,8$ \\
\hline TAPSE, мм & 11 & 14 \\
\hline УО, мл & 41 & 62 \\
\hline
\end{tabular}

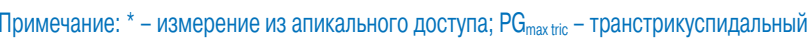
градиент; TAPSE - амплитуда экскурсии фиброзного кольца трикуспидального клапана.

Таблица 2

6-МШТ и оценка одышки до и после терапии илопростом

\begin{tabular}{|l|c|c|}
\multicolumn{1}{|c|}{ Показатель } & Исходно & $\begin{array}{c}\text { На фоне терапии } \\
\text { илопростом }\end{array}$ \\
\hline Дистанция 6-МШТ, м & 223 & 259 \\
\hline SpО $_{2}$ по 6-МШТ, \% & $95>88$ & $96>90$ \\
\hline Диспноэ (Borg) по 6-МШТ, баллы & $3>8$ & $2>6$ \\
\hline Диспноэ по шкале тМRС, баллы & 3 & 2 \\
\hline ФК ЛАГ по классификации В03 & III & II \\
\hline
\end{tabular}

По данным лабораторных анализов были выявлены лишь изменения со стороны гемоглобина крови - 159 г / л.

При проведении ЭхоКГ выявлено прогрессирование ЛГ, дилатация правого предсердия (ПП) и ПЖ и снижение ударного объема (УО) (табл. 1). По данным 6-минутного шагового теста (6-МШТ) отмечено выраженное снижение ТФН (223 м) и десатурация при нагрузках (снижение $\mathrm{SpO}_{2}$ до 88 \%) (табл. 2).

С учетом наличия несомненных признаков прогрессирования заболевания было принято решение об эскалации объема терапии - добавлении 2-го ЛАГ-специфичного препарата - ингаляционного илопроста (Вентавис ${ }^{\circledR}$, Bayer Schering Pharma AG). Вентавис ${ }^{\circledR}$ был назначен в начальной дозе 2,5 мкг на 1 ингаляцию при помощи mesh-небулайзера MicroAir NE-U22V (Omron Healthcare Inc.) с последующим (через 7 дней) повышением дозы до 5 мкг, 6-7 ингаляций в сутки в дневное время (среднее время ингаляции - 6 мин). На фоне данной терапии отмечено выраженное улучшение состояния пациентки: снижение СДЛА ( $\approx 7$ мм рт. ст.), повышение УО ( $\approx 50 \%)$, уменьшение размеров ПП и ПЖ, повышение TAPSE (см. табл.1). Положительные изменения параметров гемодинамики сопровождались улучшением клинической картины: отмечено понижение одышки в покое и при физической нагрузке, ФК ЛАГ с ІІІ до II, прирост дистанции по 6-МШТ (36 м), уменьшение выраженности десатурации (см. табл. 2) и исчезновение отеков ног.

\section{Обсуждение}

По результатам рандомизированных клинических исследований (РКИ), выполненных в последнее десятилетие, продемонстрировано, что при монотерапии специфическими препаратами повышается уровень выживаемости больных ЛАГ [10-13], ТФН, улучшаются параметры гемодинамики [10, 14-20] и увеличивается период до клинического ухудшения $[14,15,21]$. Опытом реальной клинической практики, в т. ч. отечественной, также положительно оценивается эффективность новых препаратов для терапии пациентов с ЛАГ [22].

ИЛАГ является прогрессирующим заболеванием, которое требует постоянного мониторинга и увеличения объема лекарственной терапии, если поставленные цели терапии не были достигнуты с помощью 1 препарата. Традиционно решение об эскалации терапии у больных ЛАГ основывается на фактах ухудшения клинического состояния: снижение ТФН, ухудшение гемодинамических параметров и повышение ФК ЛАГ [23-25]. Комбинированная терапия, т. е. использование $\geq 2$ препаратов разных классов, является одним из путей эскалации терапии и успешно используется при ведении таких заболеваний, как системная артериальная гипертензия, хроническая сердечная недостаточность, хроническая обструктивная болезнь легких и др. [26, 27]. Комбинированная терапия для лечения больных ЛАГ привлекательна тем, что 3 известные сигнальные системы, вовлеченные в патогенез ЛАГ ("пути" простациклина, эндотелина и оксида азота) являются потенциальными мишенями для существующих лекарственных препаратов, используемых при терапии ЛАГ. Несмотря на то, что ранние, небольшие исследования по изучению комбинированной терапии не показали ее убедительных преимуществ [28, 29], последующие работы, в т. ч. и более масштабные, позволяют сегодня уверенно говорить о высокой эффективности комбинированной терапии у пациентов с ЛАГ $[30,31]$. 
Данных о возможностях комбинированной терапии бозентаном и ингаляционным илопростом пока не так много. В двойном слепом РКИ (STEP), посвященном оценке клинической эффективности данной комбинации, которое продолжалось 12 нед., проводилось сравнение комбинированной терапии илопростом и бозентаном с монотерапией бозентаном у пациентов с ЛАГ $(n=67)$, из них $55 \%-$ с ИЛАГ [31]. Первичной конечной точкой исследования была безопасность терапии, кроме того, изучались влияние терапии на изменение дистанции по 6-МШТ, ФК по классификации ВО3, параметров легочной гемодинамики, периода до клинического ухудшения и др. Показано, что комбинированная терапия илопростом и бозентаном обладает благоприятным профилем безопасности: зарегистрированные побочные эффекты были типичны для терапии простациклинами, чаще всего был отмечен кашель (у 40 \% больных, получавших илопрост, и у $19 \%-$ в группе сравнения). По оценкам пациентов, кашель был легким / умеренным, отмены препаратов не требовалось. Кроме того, в исследовании STEP продемонстрировано значительное улучшение физической работоспособности у пациентов группы комбинированной терапии (прирост результатов 6-МШТ 26 м; $p=0,051)$, улучшение на 1 ФК по классификации ВОЗ при приеме илопроста у $34 \%$ vs $6 \%$ больных в группе контроля $(p=0,002)$ и увеличение периода до клинического ухудшения $(p=0,022)$.

\section{Заключение}

Таким образом, в представленном клиническом случае продемонстрировано, что при прогрессировании ЛАГ у пациентов, получающих поддерживающую терапию бозентаном, добавление в схему терапии ингаляционного илопроста позволяет добиться улучшения параметров легочной гемодинамики, повышения ФК по классификации ВО3, уменьшения одышки и повышения ТФН.

\section{Литература}

1. Galié N., Hoeper M., Humbert M. et al. Guidelines for the diagnosis and treatment of pulmonary hypertension. The Task Force for the Diagnosis and Treatment of Pulmonary Hypertension of the European Society of Cardiology (ESC) and the European Respiratory Society (ERS). Eur. Heart. J. 2009; 30: 2493-2537.

2. Galié N., Hoeper M.M., Humbert M. et al. Guidelines for the diagnosis and treatment of pulmonary hypertension. Eur. Respir. J. 2009; 34: 1219-1263.

3. McLaughlin V.V., Archer S.L., Badesch D.B. et al. ACCF / AHA 2009 expert consensus document on pulmonary hypertension: a report of the American College of Cardiology Foundation Task Force on Expert Consensus Documents and the American Heart Association: developed in collaboration with the American College of Chest Physicians, American Thoracic Society, Inc., and the Pulmonary Hypertension Association. Circulation 2009; 119: 2250-2294.

4. Humbert M., Sitbon O., Chaouat A. et al. Pulmonary arterial hypertension in France: results from a national registry. Am. J. Respir. Crit. Care Med. 2006; 173: 1023-1030.
5. Peacock A.J., Murphy N.F., McMurray J.J.V. et al. An epidemiological study of pulmonary arterial hypertension. Eur. Respir. J. 2007; 30: 104-109.

6. Badesch B.D., Champion H.C., Gomez-Sanchez M.A. et al. Diagnosis and assessment of pulmonary arterial hypertension. J. Am. Coll. Cardiol. 2009; 54: S55-S56.

7. Humbert M., Sitbon O., Chaouat A. et al. Survival in patients with idiopathic, familial, and anorexigen-associated pulmonary arterial hypertension in the modern management era. Circulation 2010; 122: 156-163.

8. Thenappan T., Shah S.J., Rich S. et al. Survival in pulmonary arterial hypertension: a reappraisal of the NIH risk stratification equation. Eur. Respir. J. 2010; 35: 1079-1087.

9. Tyndall A.J., Bannert B., Vonk M. et al. Causes and risk factors for death in systemic sclerosis: a study from the EULAR Scleroderma Trials and Research (EUSTAR) database. Ann. Rheum. Dis. 2010; 69: 1809-1815.

10. Barst R.J., Rubin L.J., Long W.A. et al. A comparison of continuous intravenous epoprostenol (prostacyclin) with conventional therapy for primary pulmonary hypertension. The Primary Pulmonary Hypertension Study Group. N. Engl. J. Med. 1996; 334: 296-302.

11. McLaughlin V.V., Shillington A., Rich S. Survival in primary pulmonary hypertension: the impact of epoprostenol therapy. Circulation 2002; 106: 1477-1482.

12. McLaughlin V.V. Survival in patients with pulmonary arterial hypertension treated with first-line bosentan. Eur. J. Clin. Invest. 2006; 36 (Suppl. 13): 10-15.

13. Sitbon O., McLaughlin V.V., Badesch D.B. et al. Survival in patients with class III idiopathic pulmonary arterial hypertension treated with first line oral bosentan compared with an historical cohort of patients started on intravenous epoprostenol. Thorax 2005; 60: 1025-1030.

14. Channick R.N., Simonneau G., Sitbon O. et al. Effects of the dual endothelin-receptor antagonist bosentan in patients with pulmonary hypertension: a randomised placebo-controlled study. Lancet 2001; 358: 1119-1123.

15. Rubin L.J., Badesch D.B., Barst R.J. et al. Bosentan therapy for pulmonary arterial hypertension. N. Engl. J. Med. 2002; 346: 896-903.

16. Barst R.J., Langleben D., Frost A. et al. Sitaxsentan therapy for pulmonary arterial hypertension. Am. J. Respir. Crit. Care Med. 2004; 169: 441-447.

17. Barst R.J., Langleben D., Badesch D. et al. Treatment of pulmonary arterial hypertension with the selective endothelin-A receptor antagonist sitaxsentan. J. Am. Coll. Cardiol. 2006; 47: 2049-2056.

18. Galié N., Ghofrani H.A., Torbicki A. et al. Sildenafil citrate therapy for pulmonary arterial hypertension. N. Engl. J. Med. 2005; 353: 2148-2157.

19. Galié N., Olschewski H., Oudiz R.J. et al. Ambrisentan for the treatment of pulmonary arterial hypertension: results of the ambrisentan in pulmonary arterial hypertension, randomized, double-blind, placebo-controlled, multicenter, efficacy (ARIES) study 1 and 2. Circulation 2008; 117: 3010-3019.

20. Galié N, Brundage BH, Ghofrani HA, et al. Tadalafil therapy for pulmonary arterial hypertension. Circulation 2009; 119: 2894-2903.

21. Galié N., Rubin L.J., Hoeper M.M. et al. Treatment of patients with mildly symptomatic pulmonary arterial hypertension with bosentan (EARLY study): a double-blind, randomised controlled trial. Lancet 2008; 371: 2093-2100.

22. Авдеев С.Н., Царева Н.А., Неклюдова Г.В., Чучалин А.Г. Первый клинический опыт применения антагониста рецепторов эндотелина бозентана у пациентов с легочной 


\section{OBEHTABИC}

Терапия, Аостигаюшая цели

- Простациклин с селективным действием для эффективного лечения легочной гипертензии $1,3,4$

- Выраженное улучшение при монотерапии у пациентов, не получавших лечение ранее $2,3,4$

- Минимальный риск системных побочных эффектов и лекарственных взаимодействий $\breve{~}^{3,4}$

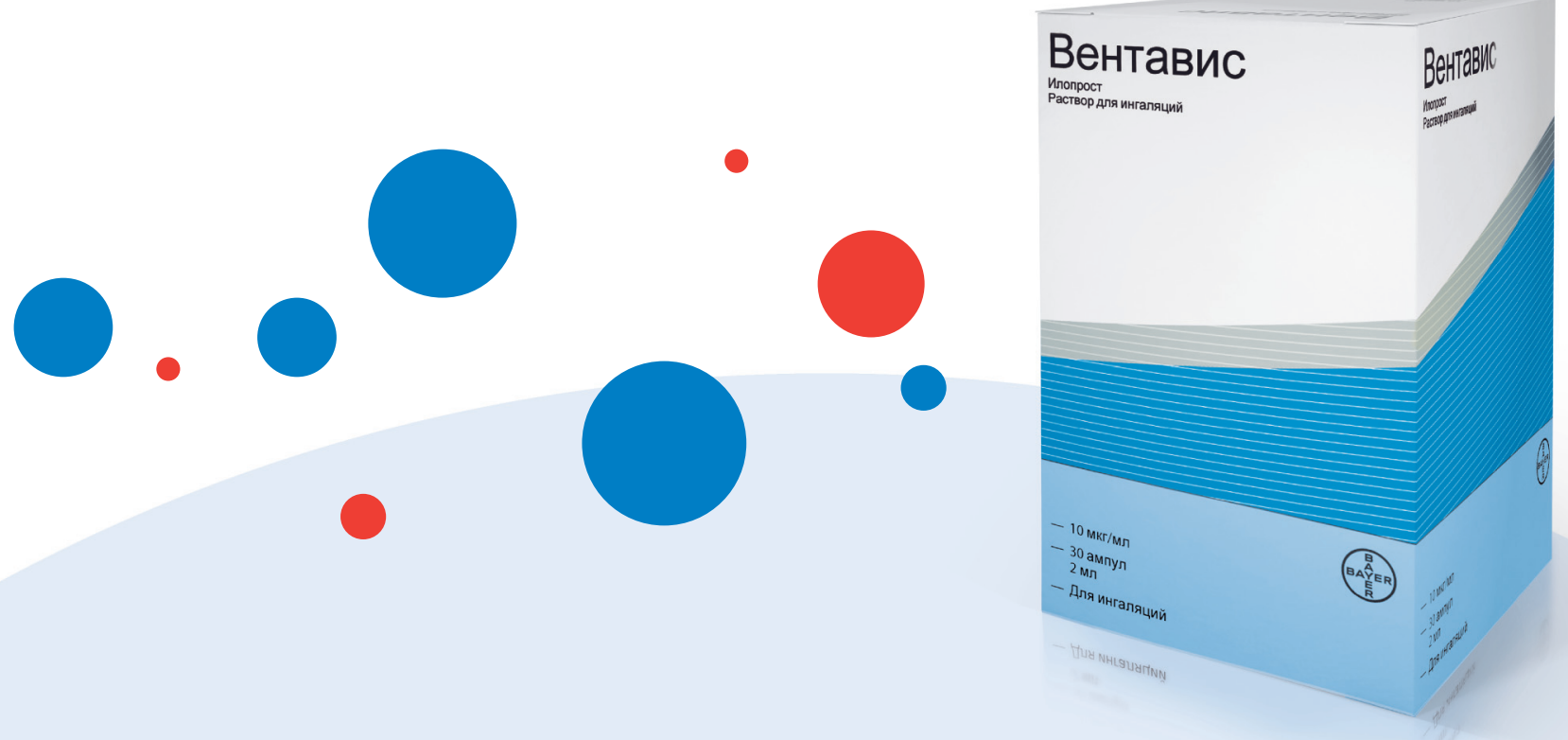

Вентавис. Международное непатентованное название: илопрост. Лекарственная форма и состав: раствор для ингаляций, 10 мкг/мл, в ампулах по 2 мл. Показания. Лечение среднетяжелой и тяжелой стадии легочной гипертензии в следующих случаях: идиопатическая (первичная) артериальная легочная гипертензия, семейная артериальная легочная гипертензия; артериальная легочная гипертензия, обусловленная заболеванием соединительной ткани или действием лекарственных средств или токсинов; легочная гипертензия вследствие хронических тромбозов и/или эмболий легочной артерии при отсутствии возможности хирургического лечения. Противопоказания. Патологические состояния, при которых воздействие препарата Вентавис на тромбоциты может повысить риск кровотечения (в т.ч. язвенная болезнь желудка и двенадцатиперстной кишки в стадии обострения, травма, внутричерепное кровоизлияние). Тяжелая ишемическая болезнь сердца или нестабильная стенокардия. Инфаркт миокарда в предыдущие 6 месяцев. Декомпенсированная сердечная недостаточность при отсутствии надлежащего врачебного контроля. Тяжелые аритмии. Подозрение на застой крови в легких. Цереброваскулярные осложнения (в т.ч. транзиторная ишемическая атака, инсульт) в предыдущие 3 месяца. Легочная гипертензия вследствие легочной вено-окклюзионной болезни. Врожденные или приобретенные пороки клапанов сердца с клинически значимыми нарушениями функции миокарда, которые не обусловлены легочной гипертензией. Повышенная чувствительность к илопросту или другим компонентам препарата. Дети и подростки до 18 лет (в связи с тем, что опыт применения ограничен). С осторожностью: Нарушение функции печени и почечная недостаточность у пациентов, нуждающихся в проведении диализа, артериальная гипотензия, ХоБЛ, тяжелая бронхиальная астма. Побочное действие. Кровотечения (главным образом в виде носовых кровотечений и кровохарканья), головная боль, головокружение, вазодилатация, гипотензия, обморок, тахикардия, ощущение сердцебиения, боль в грудной клетке, кашель, одышка, фаринголарингеальная боль, раздражение в горле, тошнота, диарея, рвота, раздражение слизистой оболочки рта и языка, сыпь, боль в челюсти/тризм, боль в спине, периферические отеки. Отпускается по рецепту врача. Регистрационный номер ЛСР-005775/10. Актуальная версия инструкции по медицинскому применению от 29.08.2013. Производитель: Байер Фарма АГ, Германия, произведено Берлимед С.А., Испания. Подробная информация содержится в инструкции по медицинскому применению.

Дополнительную информацию можно получить по адресу: ЗАО «БАЙЕР», 107113, Москва, 3-я Рыбинская ул., д. 18, стр. 2. Тел.: + 7 (495) 231 1200, факс: + 7 (495) 231 1202. www.bayerpharma.ru. Для получения подробной информации по механизму действия, побочным эффектам и другим разделам вы можете обратиться к полной инструкции по медицинскому применению препарата Вентавис.

Информация представлена в соответствии с результатами рандомизированных контролируемых клинических исследований. Термин «Выраженное улучшение» подразумевает статистически достоверное улучшение переносимости физической нагрузки и параметров гемодинамики, наблюдавшееся в клинических исследованиях ингаляционного илопроста. В частности, в исследовании AIR у пациентов с легочной гипертензией увеличение пройденной дистанции в тесте 6-ти минутной ходьбы составило в среднем +40 метров и +37 метров для пациентов c III и IV ФК, соответственно (результаты приведены с поправкой на плацебо). В исследовании AIR-2, в подгруппе пациентов с идиопатической легочной гипертензией, получавших терапию ингаляционным илопростом в течение 2 лет, общая выживаемость составила $91 \%$, по сравнению с ожидаемой расчетной выживаемостью на уровне $63 \%$

Источники: 1. Регистрационное удостоверение №лСР-005775/10 от 23.06.2010 г. 2. ESC-ERS guidelines, European Heart J 2009;30:2493-2537. 3. Olschewski H, et al. Aerosolized prostacyclin and iloprost in severe pulmonary hypertension. Ann Intern Med 1996 Мау 1; 124(9):820-4. 4. Инструкция по медицинскому применению препарата Вентавис. 
артериальной гипертензией: результаты 1-годичного исследования. Тер. арх. 2013; 3: 38-43.

23. Galié N., Torbicki A., Barst R. et al. Guidelines on diagnosis and treatment of pulmonary arterial hypertension: The Task Force on Diagnosis and Treatment of Pulmonary Arterial Hypertension of the European Society of Cardiology. Eur. Heart J. 2004; 25: 2243-2278.

24. Badesch D.B., Abman S.H., Ahearn G.S. et al. Medical therapy for pulmonary arterial hypertension: ACCP evidencebased clinical practice guidelines. Chest 2004; 126 (Suppl. 1): 35S-62S.

25. Badesch D.B., Abman S.H., Simonneau G. et al. Medical therapy for pulmonary arterial hypertension: updated ACCP evidence-based clinical practice guidelines. Chest 2007; 131: 1917-1928

26. Frishman W.H., Landau A., Cretkovic A. Combination drug therapy with calcium-channel blockers in the treatment of systemic hypertension. J. Clin. Pharmacol. 1993; 33: 752-755.

27. Pitt B., Zannad F., Remme W.J. et al. The effect of spironolactone on morbidity and mortality in patients with severe heart failure. Randomized Aldactone Evaluation Study Investigators. N. Engl. J. Med. 1999; 341: 709-717.

28. Humbert M., Barst R.J., Robbins I.M. et al. Combination of bosentan with epoprostenol in pulmonary arterial hypertension: BREATHE-2. Eur. Respir. J. 2004; 24: 353-359.
29. Hoeper M.M., Leuchte H., Halank M. et al. Combining inhaled iloprost with bosentan in patients with idiopathic pulmonary arterial hypertension. Eur. Respir. J. 2006; 28: 691-694.

30. Simonneau G., Rubin L.J., Galiè N. et al. Addition of sildenafil to long-term intravenous epoprostenol therapy in patients with pulmonary arterial hypertension: a randomized trial. Ann. Intern. Med. 2008; 149: 521-530.

31. McLaughlin V.V., Oudiz R.J., Frost A. et al. Randomized study of adding inhaled iloprost to existing bosentan in pulmonary arterial hypertension. Am. J. Respir. Crit. Care Med. 2006; 174: 1257-1263.

\section{Информация об авторах}

Авдеев Сергей Николаевич - д. м. н., профессор, руководитель клинического отдела ФГБУ "НИИ пульмонологии" ФМБА России; тел. / Факс: (495) 465-52-64; e-mail: serg_avdeev@list.ru

Царева Наталья Анатольевна - к. м. н., заведующий лаборатории интенсивной пульмонологии и дыхательной недостаточности ФГБУ "НИИ пульмонологии" ФМБА России; тел.: (495) 465-74-15; e-mail: n_tsareva @mail.ru

Неклюдова Галина Васильевна - д. м. н., ведущий научный сотрудник лаборатории функциональных методов исследования ФГБУ "НИИ пульмонологии" ФМБА России; тел.: (495) 465-53-84; e-mail: nekludova_gala @mail.ru

Поступила 15.01.14 ( ) Коллектив авторов, 2013 удк 616.131-008.331.1-085 